\title{
Treating Macular Degeneration with Chinese Medicine
}

\author{
Andy Rosenfarb* \\ Department of Chinese Medical Opthalmology, Zhejiang College of Chinese Medicine in Hangzhou, China
}

Submission: December 16, 2016; Published: January 19, 2016

*Corresponding author: Andy Rosenfarb, Department of Chinese Medical Opthalmology, Zhejiang College of Chinese Medicine in Hangzhou, China, Email: Acupunkk@aol.com

\section{Macular Degeneration}

Macular Degeneration (ARMD-Aged Related Macular Degeneration) is the slow deterioration of the cells in the macula, a tiny yellowish area near the center of the retina. The macula functions to give us clear central vision and fine detailed images. The deterioration of the macula affects an individual's central vision - the ability to read, write and drive and recognizing faces - among other visual abnormalities. There are two types of macular degeneration, wet and dry. Ninety percent of people with macular degeneration have the dry-type in which small, yellow spots called Drusen form underneath the macula. Drusen are believed to be metabolic waste products that accumulate and cause cellular damage. It has been suggested that Drusen slowly breaks down the cells of the macula, causing distorted vision.

Dry macular degeneration can progress into the second, more severe type, called wet-type macular degeneration. The cause of this progression is unknown to conventional medicine. In wettype ARMD, new, abnormal blood vessels begin to grow toward the macula, causing rapid and severe vision loss. These weak blood vessels can rupture and bleed, thus "wet-type" ARMD. Both wet and dry ARMD are diagnosed by an ophthalmologist and there is currently no safe and effective conventional treatment.

Individual risk factors for macular degeneration have been identified as contributing factors to the development and progression of ARMD. These include: female gender, smoking (increase risk by 200-300\%), diabetics, high blood pressure (uncontrolled) and family history of macular degeneration.

\section{Chinese Medicine and Macular Degeneration}

In my experience Chinese Medicine can offer a very effective treatment for both types of ARMD. Although this kind of treatment will not help every single ARMD case presented, my personal success rate has been at least $80 \%$. By success I mean that there are either subjective and/or objective measurable improvements in a person's vision after a series of treatment.
There are many simple ways to test vision that are well within our scope of practice as acupuncturists; two being Visual Acuity Test (eye chart) and an Amsler Grid Test. The clinical objective in treating ARMD is to treat the root cause of the disease pattern. The branch treatment or temporary solution can be to activate the blood circulation in order to resolve stagnation. Visual capacity may be improved by promoting the circulation in choroids and retina, preventing cell death, and reversing the inability to absorb and circulate vital nutrients for healthy vision.

ARMD (wet and dry) is most often an exhaustion of the body's Yin. The Yin aspect of the visual field is the central vision, and the peripheral vision is more Yang in nature. When the central vision goes, it indicates a "burn-out" of Kidney and Liver Yin, so using Chinese herbs that nourish Yin seems to work best (Figure 1).

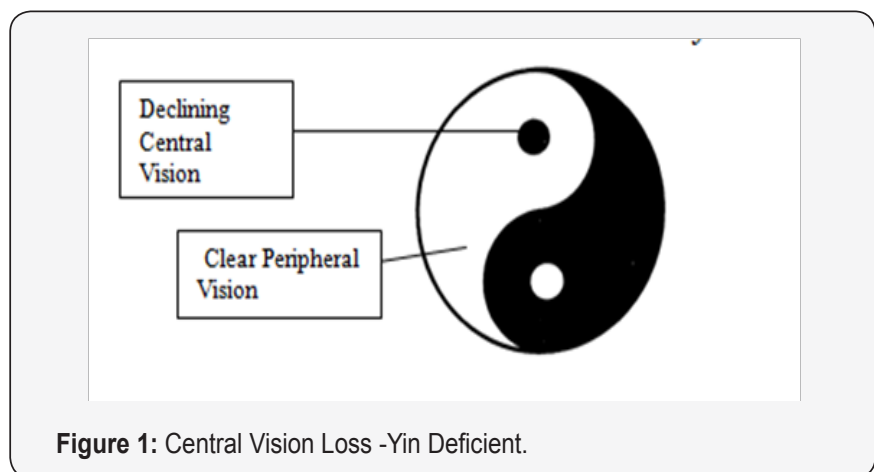

The function of the Spleen (supported by the Kidney) is to transform and transport nourishment that is ingested. When working towards generating Yin in the body, it is essential that the Earth element (spleen-pancreas and stomach) be in a state of optimal function. The process of breaking down food into usable nourishment for the cells of the body requires a digestive system. It has been stated in the Pi Wei Lun by Li Ding Yuan that as we age, our earth element (digestive function) weakens. When the 
body's capacity to break down food becomes less efficient, the ability to replenish Yin and Blood can compromised as a result of poor digestion. Again, ARMD is generally seen as Yin deficiency cause by a "starvation" with an impaired transformation and transportation function.

The yin deficiency typically leads to a progressive drystagnation of Qi and Blood - the later stages in the development of ARMD. The blood vessels of the eye often become so dry and brittle that they can leak blood or burst altogether, thus giving rise to the less common "wet ARMD." One of the key ways to observe if a patient with dry-type ARMD is susceptible to developing wet-type ARMD is to see if they tend to bruise easily. If they do in fact bruise easily (and have a history of bleeding disorders or have been over-dosed on blood thinners), they have a higher probability of developing wet-type ARMD. If bleeding occurs the following steps should be taken AFTER the patient has been stabilized by their ophthalmologist. In cases of wet ARMD, if the bleeding is severe they will need laser treatment to arrest the bleeding. If the bleeding is light and the patient has previously seen their ophthalmologist, you can suggest snail shell moxa techniques - developed by Shmuel Halevi in Isreal.

Once the bleeding has stopped, the next step is to nourish the Yin and invigorate the Qi and blood with acupuncture and Chinese herbal medicine. An herb like Chinese Notoginseng (Sanqi) would be a good choice for wet ARMD, whereas Dan Shen based formulas work better for dry ARMD. You can then follow up with digestive tonic formulas and yin-nourishing formulas, based on the dominating TCM pattern. These formulas should be taken long term (6-12 months), as it can take time to build the Central Qi, and generate Yin.

\section{Acupuncture Treatment}

Body Points:

A. Distal: Li-3, Si-3, Ht-8, SJ-3, Sp-3, Ki-1, Sp-6, St-36

B. Local: UB-2 (same effect as UB-1), Yuyao, GB-14,Yintang

C. Ear Points: Adrenal, Pt. Zero, \& Corpus Callosum

\section{Electro-Acupuncture}
A. E-Stim \#1: UB-2 to Alt Point - 1 finger medial to St-2
B. E-stim \#2: SJ-23, Tongming ( $1 / 2$ cun below GB-1)

Note: I recommend using a Pantheon 4C E-Stim Device, where the points are stimulated at a constant $2 \mathrm{~Hz}$ for $20-30 \mathrm{~min}$.

Caution: Please DO NOT use local electro-acupuncture on patients with retinal bleeding or elevated inter-ocular pressure (IOP)/ glaucoma. It can cause bleeding in weak vessels and raise IOP (Figure 2).

*Snail shell moxa can be done daily of every other day for 1-2 weeks with the presence of retinal bleeding. The patient should feel the warmth of the moxa burning.

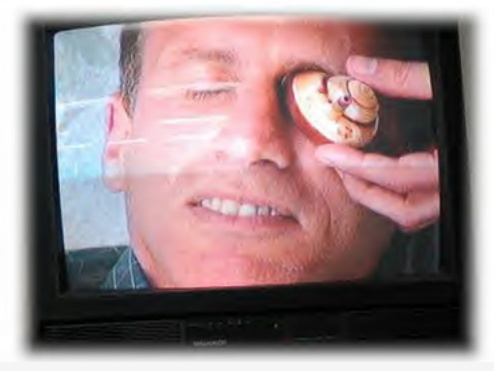

Figure 2: Snail Shell Moxa Treatment for Light Retinal Bleeding.

\section{Chinese Herbal Medicine - Base Formulas:}

\section{Wet ARMD}

i. Yunnan Paiyao or Sanqi Powder (dissolve 2 g 2x/day in water)

ii. Ming Mu Di Huang Tang (Bright Eye Tea)

iii.

Shu Gan Tang + Erchen Tang (Soothe the Liver Tea +

Two Aged Tea)

iv. Xiao Yao San

v. Bu Zhong Yi Qi Tang

Dry ARMD

A. Ming Mu Di Huang Tang (Bright Eye Tea)

B. Shu Gan Tang (Soothe the Liver Tea) + Er Chen Tang (

Two Aged Tea)

C. Dan Shen Pain

D. BuZhing Yi Qi Tang

NOTE: These are only guidelines and suggested base formulas. Chinese herbal formulas are most effective when tailored to each patients needs based on your TCM diagnosis.

*Dr. Andy Rosenfarb specializes in treating degenerative eye conditions and is the author of "Healing Your Eyes with Chinese Medicine," “Ophthalmology in Chinsese Medicine," “Acupuncture Treatment for Macular Degeneration: Clinically Proven Methods to Recover \& Preserve Retinal Health," and "Acupuncture Treatment for Retinitis Pigmentosa: How a Scientifically Proven Acupuncture System is Recovering and Preserving Vision," and "The Black Book of Micro Acupunture 48."

For more questions and more information on treating ARMD with Chinese Medical Ophthalmology please contact him at www.rosenfarbclinic.com 
Your next submission with Juniper Publishers will reach you the below assets

- Quality Editorial service

- Swift Peer Review

- Reprints availability

- E-prints Service

- Manuscript Podcast for convenient understanding

- Global attainment for your research

- Manuscript accessibility in different formats

( Pdf, E-pub, Full Text, Audio)

- Unceasing customer service

Track the below URL for one-step submission https://juniperpublishers.com/online-submission.php 